\title{
Undergraduate Research for All: Addressing the Elephant in the Room
}

\begin{abstract}
The positive impact of undergraduate research on students' success in college is well documented. Many, however, have questioned the traditional apprentice-style model of undergraduate research, raising concerns about who gets these experiences, how the experiences enhance scientific capability and student persistence, and how these experiences might be improved to get more "bang for the buck" in terms of a higher-performing scientific workforce. Research experiences are usually geared toward selected students, such as those entering graduate or professional schools. Where does that leave the vast majority of STEM students who graduate at the baccalaureate level and join the workforce? In this article, we will describe an assessed model used at Georgia Gwinnett College that provides all STEM-undergraduates (regardless of their career goals) with four years of research experiences in a cost-effective manner that we believe will result in students who are better prepared to contribute to the scientific workforce at all levels.
\end{abstract}

Georgia Gwinnett College's School of Science and Technology (SST) is currently engaged in a comprehensive pilot project designed to improve STEM (science, technology, engineering, and mathematics) learning and student engagement in the classroom. Central to our model is the growing body of evidence that shows links between student research and lasting learning and indicates that research experiences increase students' interest in careers in STEM fields (National Research Council 2003; Lopatto 2007; Lopatto 2009; Laursen et al. 2010). Lopatto (2007) points out that even a short immersion in undergraduate research is enough to effect long-term gains in students' motivation for learning, independence, and understanding of science. These experiences also play a significant role in alumni getting into graduate school, being employed, or both (Schmitz and Havholm 2015).

While there is widespread agreement that STEM programs should provide undergraduates with research experience, obstacles exist, both financial and temporal. The traditional faculty mentor/apprenticeship model typically requires significant financial and faculty resources, especially for institutions where teaching is the primary focus. Faculty at public four-year colleges typically have heavy teaching and service loads, limited research resources, and the ability to mentor only a few independent research students. Research experiences are also typically available only for selected students

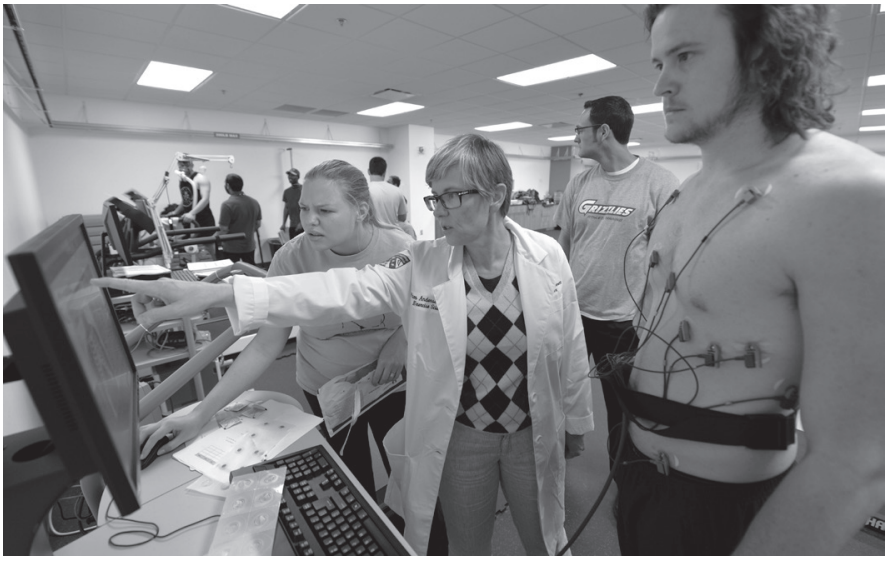

Dr. Pamela Andersen working with students in the exercise science lab.

intending to go to graduate school, thus neglecting the majority of students (Linn et al. 2015). Further, many students, particularly those from underrepresented populations, may not seek out research opportunities because they lack the confidence and skills to do so. These obstacles represent the "elephant in the room," that is, the lack of inclusiveness and the unavailability of research opportunities for all students who will graduate and join the workforce. Here we describe an innovative approach that provides research experiences for all STEM students, over multiple semesters, in a cost-effective manner that results in measurably better-performing students.

\section{A Four-year Undergraduate Research and Creative Experience Model}

One approach to overcoming the challenges described above is to supplement more traditional faculty-mentored research with undergraduate research experiences embedded in existing courses. Such projects provide a mechanism for successfully engaging large numbers of students in undergraduate research and providing them with the skills and confidence to seek out independent, faculty-mentored research or alternative summer research opportunities (Bangera and Brownell 2014; Caudill et al. 2010; Goldey et al. 2012; Shaffer et al. 2014). This model is also replicable and achievable at a variety of academic institutions.

The Four-year Undergraduate Research and Creative Experience (4YrURCE) Model at Georgia Gwinnett College (GGC) is a pilot project that takes the idea of course-embed- 


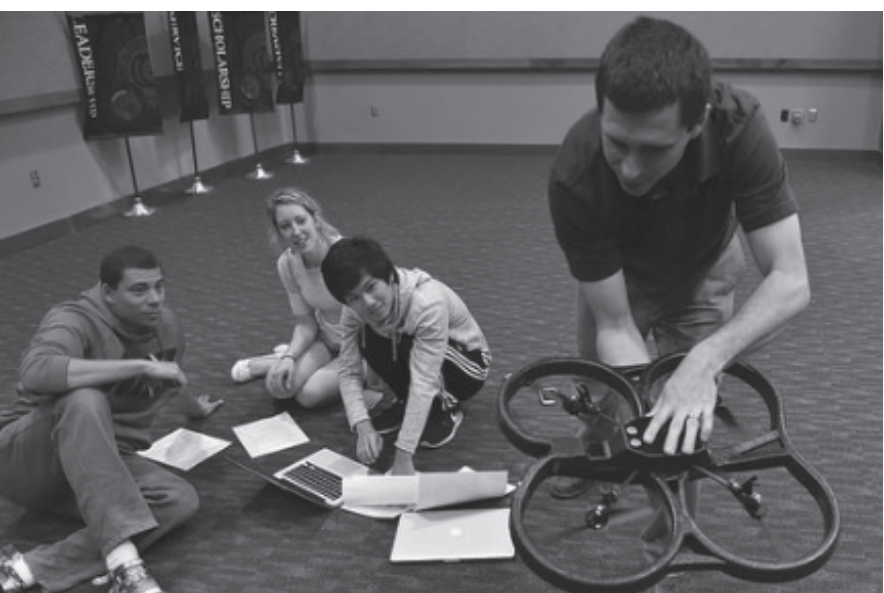

Dr. Siva with students learning to program drones.

ded research experiences one step further by creating a model that systematically scaffolds course-embedded research and creative experiences with increasing complexity for every STEM major in each of the four years of their undergraduate program (Leader et al. 2014; Runck et al. 2014). The design of this model provides all STEM students opportunities to engage in research and creative experiences that address specific STEM competencies (research skills, creative abilities, and core-content knowledge) that students are expected to master by the end of each course.

The definition of "research experiences" has been well debated, but for our purposes we wanted students to develop research skills and competencies through research experiences that are novel to them. We include the term "creative experiences" for disciplines such as information technology that engage students in creative activities rather than research activities (for example, the creation of apps, games, animations, etc.).

The research/creative experience model is implemented specifically for each disciplinary major (GGC does not have academic departments; faculty are grouped into academic disciplines, however). Faculty in each discipline in SST (biology, chemistry, information technology, mathematics, and exercise science) identified a four-year sequence of courses required for all students majoring in each track of each discipline. As an example, the sequence for the general biology track is shown in Figure 1. By re-designing these required courses to contain course-embedded undergraduate research, all students majoring in the general biology track will be exposed to multiple research experiences during their formative years, culminating in required independent research courses (such as STEC 4500, BIOL 4570, BIOL 4560, shown in Figure 1). STEC 4500 is the traditional faculty-mentored independent research course. BIOL 4570 and BIOL 4560 are modeled after the independent research course but focus on large-scale projects that involve 10 to 12 students.
Figure 1. Research Model's Course Sequence for General Biology

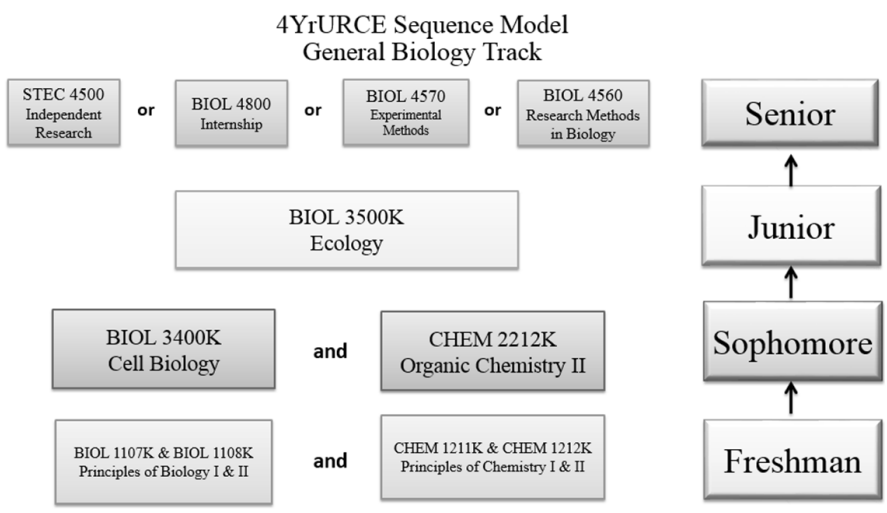

Following identification of the four-year sequences, each discipline developed a list of discipline-specific research/creative skills considered essential for students to be successful and productive in the STEM workforce and professional and graduate school. These skills, along with content knowledge linked to course goals and lesson objectives, comprised the desired STEM competencies for each discipline. Material to teach these skills and competencies was developed and guided by external influences (e.g., discipline-specific guidelines such as Vision and Change in Undergraduate Biology Education and the American Chemical Society Guidelines, as well as internal needs). The internal needs included the desire for scaffolding and vertical alignment of skills and competencies between lower-level and upper-level courses. Development of this model was faculty-driven and coordinated by a committee that included members from each discipline. As students progress through four years, they receive repeated exposure to the scientific process through inquiry; gradually build research skills, problem-solving ability and the confidence to do independent research; and by the time they graduate should have acquired various STEM competencies that are applicable to all careers.

\section{Implementation of the Model}

To complete and implement the model, faculty in all disciplines were asked to re-design their course curricula to embed research or creative experiences over a period of four years and to include discipline-specific research skills. Courses listed in the four-year sequences were targeted as priority courses for re-design. To encourage faculty buy-in, the STEM committee developed an internal structured STEM mini-grant program using funds from the University System of Georgia's STEM Initiative. Mini-grants have been shown to be an effective mechanism for stimulating STEM faculty to modify their introductory courses to include more active-learning strategies, and also to provide faculty with incentives to become more involved in research on STEM ed- 
ucation (Henry 2010). Our faculty-survey data indicate similar results (Awong-Taylor et al. 2015). Faculty members have submitted 156 mini-grant proposals over the past four years, and 109 proposals have been funded, with an average award of about $\$ 4,000$ per proposal. Funds were used to purchase new equipment and to pay for faculty release time, student assistants, and travel.

The mini-grants also provided opportunities for scholarly work and faculty collaboration on teaching and learning. The grants were competitively funded through a structured request-for-proposals (RFP) and review process. Proposals were required to include a research plan that described activities linked to research skills and a rigorous data-collection and assessment plan. Many embedded research activities have been developed as a result of this project. Some included the entire laboratory component of a course, while others included modules of laboratory sessions in certain designated sections of the course. Other changes were implemented only in lectures. Some embedded research experiences have subsequently been implemented course-wide by all instructors, while others remain in a developmental pilot stage.

This model has also promoted interdisciplinary collaborations among different disciplines and across schools. For example, faculty in information technology and biology collaborated to develop apps and animations to help biology students better understand concepts (Heinz and D'Costa 2015). In another project, exercise science students in a biomechanics course engaged in a research project using movement analysis to show physics students how research data could be used to improve their skills in golfing. Movement analysis is a critical skill in exercise science research that students utilize in physical therapy, athletic training, strength and conditioning, and health fitness. Physics students experienced how data in movement analysis are collected and acquired "real world" experience in analyzing this type of data for application of theories learned in class.

\section{Evaluation, Assessment and Preliminary Results}

During the four years of the project, more than 70 percent of faculty in the School of Science and Technology have participated in this initiative, 3,435 students (unduplicated headcount) have been impacted, and faculty have worked to revise 41 courses to include research experiences. Many of these courses are listed in our model sequences; many are freshman and sophomore courses, and several have an interdisciplinary approach. To date, most disciplines have developed prototype models, and new curricular tracks (for example in environmental science and interdisciplinary science) are currently under development.

Student achievement data and the following assessments were used to evaluate this project.

Student Attitudinal Surveys. IRB-approved student surveys were developed using questions from published surveys

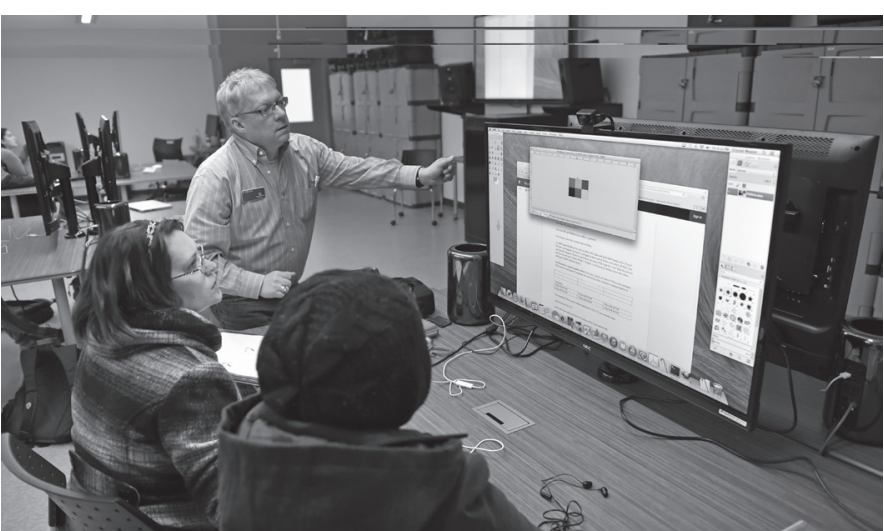

Dr. Bob Lutz and students engaging in hands-on access to technology in the digital media lab.

(Russell 2005; Pacifici and Thomson 2011). Attitudinal surveys included 28 questions that addressed three areas: attitudes about STEM, research skills and experience, and scientific literacy. Students in all re-designed courses were given pre-course and post-course surveys over the four years of the project. The attitudes of 355 students who took the survey in fall 2012 were compared to students who were juniors in fall 2015. Results indicate that as students progressed from their freshman year to their junior year, their attitudes showed significant increases regarding 27 of the 28 questions asked. The twelve questions showing the most significant attitudinal changes are shown in Table 1.

\section{Table 1. A Sampling of Attitudinal Questions Showing Average Change in Attitudes from Freshman to Junior Status}

Change in Attitude from Freshmen to Junior Status (Sample from 28 questions)

\begin{tabular}{|l|c|c|c|}
\hline \multicolumn{1}{|c|}{ Question } & Mean-Pre & Mean-Post & $\%$ Change \\
\hline I am comfortable talking about science with other students. & 3.90 & 4.37 & $31.07^{*}$ \\
\hline $\begin{array}{l}\text { As a result of my research experience I am more likely to choose a career } \\
\text { in a STEM field (Science, Technology, Engineering, Math). }\end{array}$ & 3.60 & 4.23 & $29.80^{*}$ \\
\hline I understand the variety of scientific career paths in STEM. & 3.86 & 4.25 & $28.29^{*}$ \\
\hline I would be interested in taking non-required elective courses in this field. & 3.44 & 4.17 & $25.31^{*}$ \\
\hline I like to discuss science topics with my friends and family. & 3.85 & 4.49 & $23.30^{*}$ \\
\hline I have a better understanding of the requirements of scientific writing. & 3.79 & 4.33 & $22.56^{*}$ \\
\hline $\begin{array}{l}\text { I feel confident in my ability to analyze data and design new experiments } \\
\text { or projects based on that data. }\end{array}$ & 3.81 & 4.19 & $21.91^{*}$ \\
\hline I understand inquiry and the nature of scientific investigation. & 3.85 & 4.32 & $18.79^{*}$ \\
\hline I am confident of my qualifications for jobs in related fields. & 3.76 & 4.18 & $18.37^{*}$ \\
\hline I can design and carry out my own experiments or projects. & 3.75 & 4.14 & $18.35^{*}$ \\
\hline $\begin{array}{l}\text { My skills/abilities in working independently have increased as a result of } \\
\text { my research experience. }\end{array}$ & 3.90 & 4.32 & $18.26^{*}$ \\
\hline $\begin{array}{l}\text { I understand the difference between primary literature and secondary } \\
\text { literature and know when it is appropriate to use them. }\end{array}$ & 3.67 & 4.29 & $18.03^{*}$ \\
\hline I am interested in graduate school. & 4.19 & 4.34 & 0.42 \\
\hline
\end{tabular}

Mean-Pre refers to attitude prior to coursework with embedded research experiences; mean-post refers to attitude after such experiences. Likert-scale range: 1 (strongly disagree) to 5 (strongly agree). * Significant at $p<0.05$

The only attitude that did not show a significant increase following course-embedded research was the statement "I am interested in graduate school" (0.4 percent increase). Since the pre-course value was already high (4.19 on a 5-point scale), however, this could account for the lack of change. The absence of a positive change in desire to attend graduate 


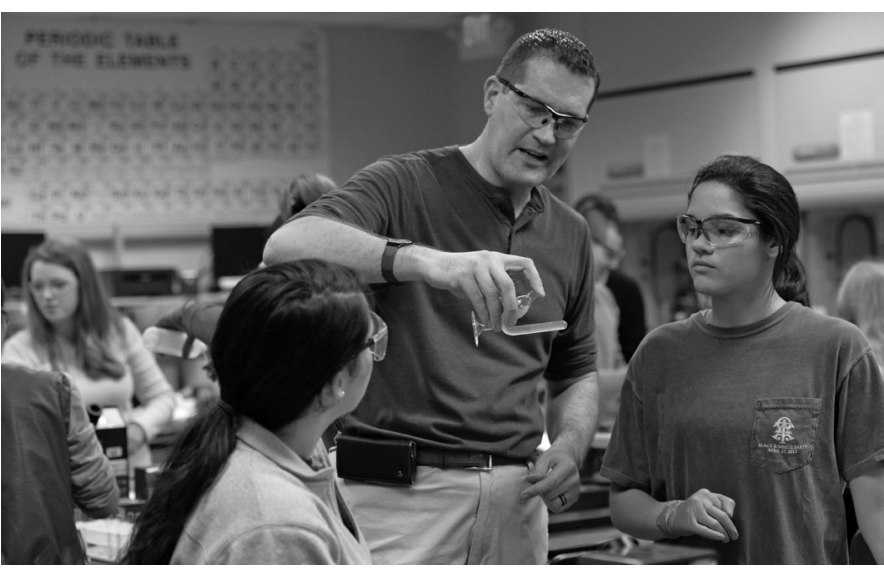

Dr. Richard Pennington demonstrating use of a fermentation tube in his Organic and Biochemistry Survey class.

school is in direct contrast to reports that suggest that students who complete a more traditional faculty-mentored research project tend to be more interested in graduate school and gain the confidence through mentoring to complete independent research (Lopatto 2004; Craney et al. 2011). This raises an interesting question as to whether course-embedded research experiences are as effective as the traditional faculty-mentored model in increasing students' interest in graduate school. As a result of this survey, we intend to focus more effort on mentoring students concerning graduate school.

Assessment of Course Content. Principal investigators (PIs) of mini-grants were asked to develop both content and student attitudinal assessments for all redesigned courses. Results from individual mini-grants indicate that the revised curriculum model has had a positive impact on student engagement and student success. Faculty have published the results of their mini-grant projects (Boindala et al. 2015; Meso et al. 2013; Russell et al. 2015, Sloop et al. 2013) and presented more than 237 talks/posters over four years at regional and national conferences. In the following we briefly describe two examples of successful projects.

The laboratory portion of Organic Chemistry II was redesigned to eliminate a series of independent, named reactions (Grignard, a Wittig, a Diels-Alder, etc.) and replace them with a semester-long, multi-step synthesis project during which students selected a target molecule, researched possible approaches to synthesis, developed experimental procedures, conducted the synthesis, and characterized their product. An Organic II synthesis problem set was used to compare student performance pre- and post-implementation of the synthesis project. Students (549) who completed the synthesis project scored better on the end-of-semester, three hour long, synthesis exam (an average 79.4 percent) than students
(244) who did not participate in the synthesis project (who scored average of 70.6 percent) on that same exam.

James Russell et al. (2015) used an integrated, course-embedded research experience to bridge two biology classes (cell biology and ecology). Over a two-year period, students analyzed arthropod biodiversity using traditional taxonomy and DNA barcoding. Within a semester, students in both courses collaborated on identification of arthropod species and uploaded their findings to an online database containing species descriptions and photographs, genetic "bar-code" data, and estimates of biodiversity across time and space. Assessment data from four semesters showed that students in the sections of the course with embedded research experiences had greater gains in content knowledge than the other students. Attitudinal surveys indicated significantly greater gains among students in research-embedded sections of the course in understanding the nature of science, in problem solving, and in conducting a research project. In general, for most of our mini-grants, results indicate that incorporating research into classroom experiences increases students' interest in research and increases students' confidence in their ability to engage in research in the future.

\section{Table 2. STEM Retention: All STEM Students Versus Underserved STEM Students}

\begin{tabular}{|c|c|c|}
\hline $\begin{array}{c}\text { Fall } \\
\text { Cohort }\end{array}$ & $\begin{array}{c}\text { STEM Retention } \\
\text { All STEM Students }\end{array}$ & $\begin{array}{c}\text { STEM Retention } \\
\text { Underserved STEM } \\
\text { Students }\end{array}$ \\
\hline 2011 & $88 \%$ & $91 \%$ \\
\hline 2012 & $83 \%$ & $85 \%$ \\
\hline 2013 & $79 \%$ & $79 \%$ \\
\hline 2014 & $86 \%$ & $83 \%$ \\
\hline
\end{tabular}

Student-Achievement Data. Preliminary analysis of student-achievement data indicate that our model may have a direct positive impact on students' GPA and retention of students in STEM disciplines. Within the School of Science and Technology, the fall 2011 cohort of STEM students showed an annual GPA increase from 2.68 (fall 2011) to 2.87 (fall 2012 ) to 2.96 (fall 2013). STEM students were also retained at a higher rate than the general student population. Over the past four years, the average retention rate of STEM students was consistently higher (84.3 percent of students retained) than that of GGC's general student population (57.5 percent). Even more compelling is the fact that the average fouryear retention rate of SST's underserved student population (84.4 percent) is also higher that GGC's retention rate overall for underserved populations (64.7 percent). Additionally, 


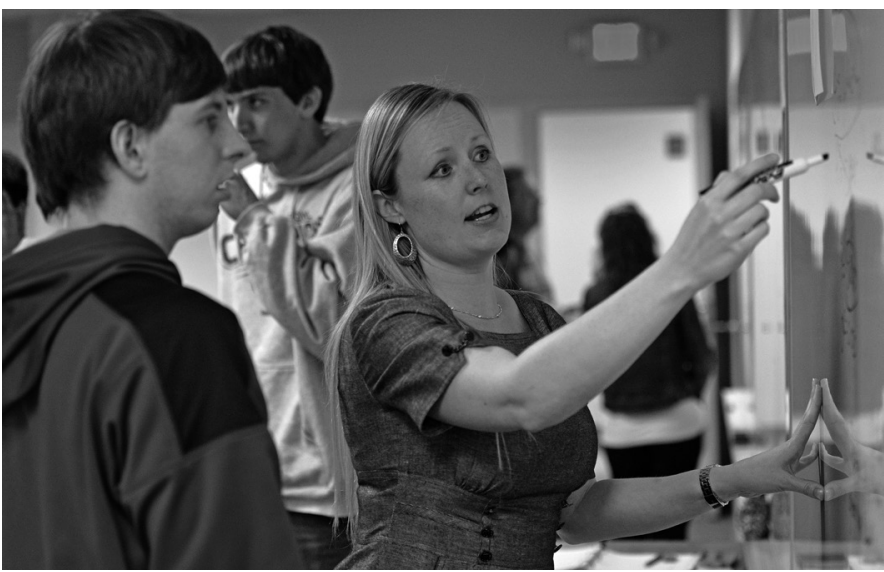

Dr. Jennifer Sinclair working with students in her mathematics lecture class.

within SST, retention of underserved students was higher or similar to the retention rates of all STEM students (Table 2). This supports the work of Jones et al. (2010) that shows that while research experiences energize biology students to stay in their major, these experiences have a greater effect on biology students from minority groups than the general population of students. Early participation in research (freshman and sophomore years) has been shown to be influential in students staying in a STEM major. First-time, full-time freshman retention rates also show similar trends (Figure 2).

Figure 2. First-time, Full-time Freshmen Retention Rates of STEM (SST) Students Versus GGC's Student Population

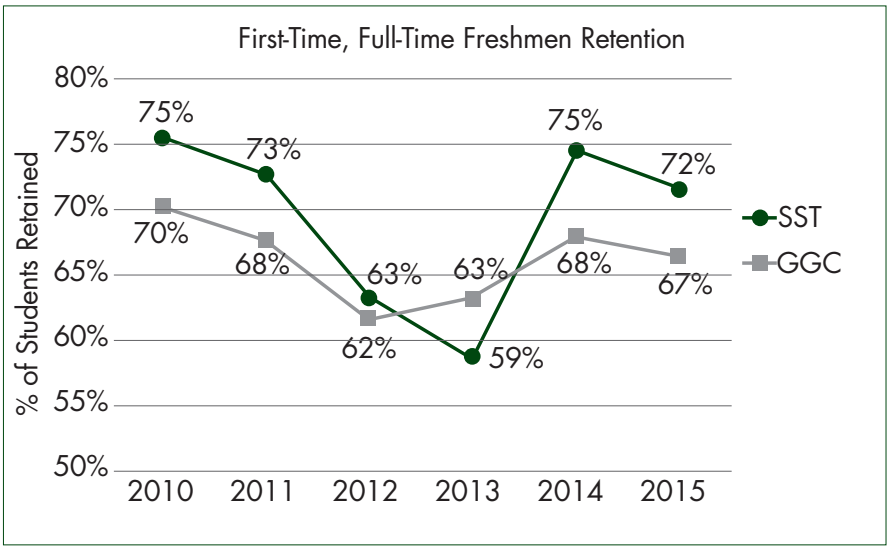

STEM student enrollment (Figure 3) has consistently increased over the past five years, with higher percentage increases than overall GGC enrollment. STEM degrees awarded also show similar trends (Figure 4). These results are promising given the grim nature of STEM's leaky pipeline nationally.
Figure 3. Percent Increase in Student Enrollment Since Fall 2010

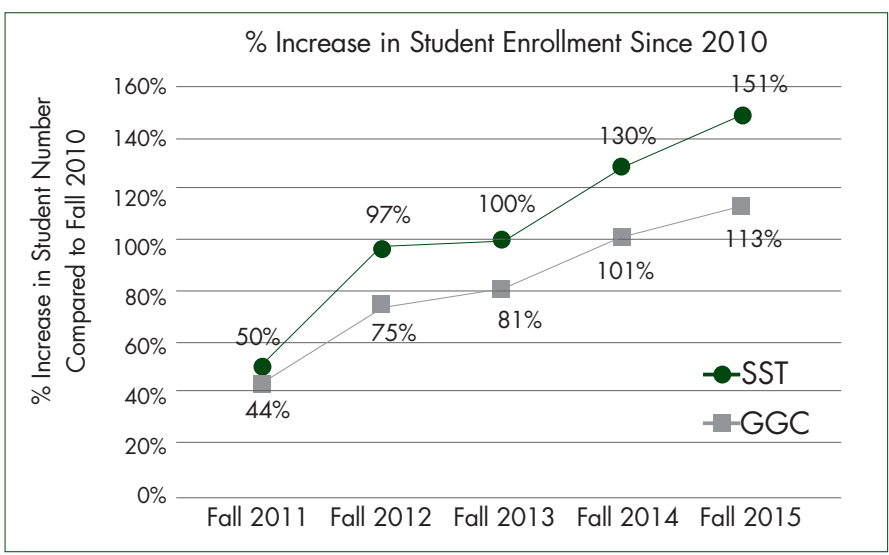

Faculty Attitudinal Survey. One goal of the project is to encourage faculty to become more engaged in the scholarship of teaching and learning and to reflect on how they teach and engage their students. To determine if faculty attitudes changed over time, we developed and administer an IRBapproved faculty attitudinal survey each spring. Survey data includes faculty demographics; awareness of STEM initiatives in the University System of Georgia (USG) and in SST; STEMrelated scholarship; and disciplinary perspectives on STEM.

Figure 4. Percent Increase in Degrees Awarded Since Fall 2010

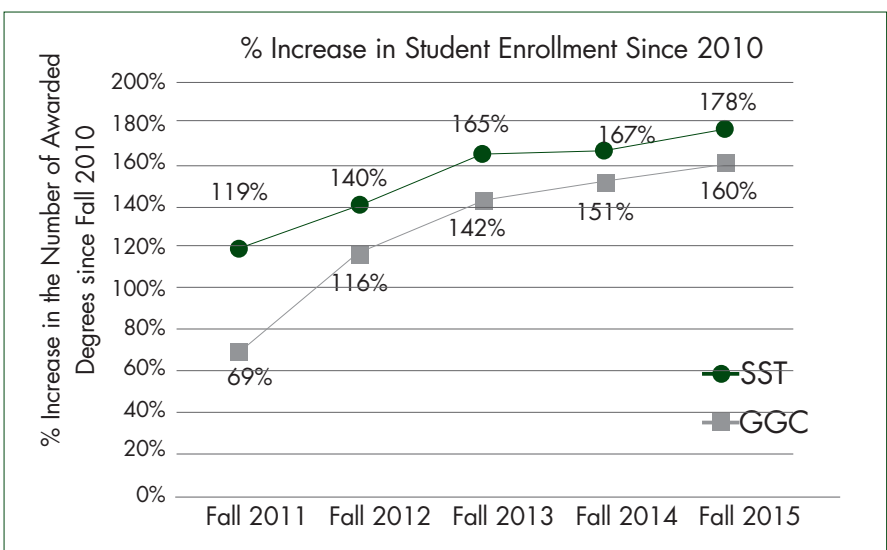

Results indicate that as use of the course-embedded research model is progressing, faculty have (1) developed a better understanding of our initiative; (2) collaborated more with other faculty; (3) participated in more and varied STEM initiatives (e.g., mini-grants, engaging with colleagues, and working in K-12 schools); (4) reported increasingly more positive attitudes toward SST'S STEM initiative and the model; (5) utilized strategies derived from the scholarship on teach- 
ing and learning in their classes; and (6) became more motivated to include different pedagogical approaches in their classrooms. In fact, 95 percent of faculty members surveyed say that this initiative has caused positive changes in their course designs, and 85 percent report seeing an increase in students' engagement.

Faculty members' concerns include finding ways to implement the initiatives given their work schedules and concerns as to whether the work is valued as research and in promotion decisions. These are valid concerns and the dean of the School of Science and Technology has committed to developing and evaluating their course-embedded research experiences as scholarly work in annual evaluation and promotion decisions.

\section{Challenges Ahead}

There are many challenges in reimagining STEM education and undergraduate research at such a robust level and at the same time promoting programmatic and cultural change. Here we briefly describe three key challenges and how they were addressed.

Faculty Buy-in. To convince faculty that such a model could be successful, the dean presented his vision bolstered by evidence-based research indicating that a four-year research experience was likely to yield positive results. Through grassroots efforts, faculty across all ranks and disciplines began exploring the vision formally through committees and informally through campus networking. Inspired by interest across the faculty, an interdisciplinary faculty committee was formed and development of the four-year model was then assigned to the disciplines. Faculty developed lists of STEM skills and competencies and identified specific courses within each academic program (see, for example, Figure 1) that offered the greatest potential to impact students.

Incentivizing and Changing the Culture of Faculty. Faculty at primarily undergraduate institutions (PUIs) are often assigned heavy service, teaching, and advising loads, leaving little time for scholarly endeavors. To encourage faculty to develop and implement course-embedded research, the STEM minigrant program (described above) was used as leverage to give faculty incentives to engage in research into teaching and learning as they redesigned their courses. Interdisciplinary and multi-faculty projects were encouraged, leading to collaborations and sharing of workloads when developing and implementing their revamped courses. Further, the dean's commitment to support and reward faculty who developed new and innovative ways to engage their students has played a critical role in overcoming this challenge.

Our faculty-survey data indicate that a student-centered learning approach to STEM education is now a norm among
SST faculty and that faculty members feel empowered to reimagine STEM education. Over the past four years, faculty have produced eight publications (with many others in the pipeline) and have done 237 presentations, many including students presenting their research experiences. A year-end, day-long STEM symposium also allows faculty to showcase their efforts and inform colleagues of their progress in developing, implementing, and assessing the course-embedded research experiences.

Trading Course Content for Research Experiences. Depth versus breath is a well-debated topic in K-16 education. Many faculty members remain concerned about the trade-off between teaching "course content" and offering "research experiences." Implementing a more interactive, student-centered approach to teaching requires faculty to cover less material; thus, a key concern is maintaining rigor in the curriculum. However, reports indicate that a shift from faculty-centered teaching to student-centered learning provides students opportunities to acquire many of the STEM competencies that are important to be successful in the workforce.

Overcoming this particular challenge required grassroots efforts by some faculty as well as providing formal faculty-development opportunities to help faculty learn more about ways to transform their classrooms. GGC's Center for Teaching Excellence provides workshops and programs that promote the design and implementation of creative learning environments and supports implementation of effective instructional practices. Additionally, the annual SST STEM Symposium offers workshops and opportunities for faculty to discuss how best to make courses more concept-oriented and focus more on integrating factual knowledge within those concepts. Anecdotally, faculty are becoming more receptive to including research experiences in lieu of content coverage and are finding ways to incorporate the content in the context of a research question that develops critical thinking.

\section{Sustainability and Transferability}

We acknowledge that sustainability is a key challenge to any pilot program. The structured mini-grant approach to competitively fund course reform gives faculty incentives to be innovative and creative. Newly designed courses embedding research and creative activities are evaluated by disciplinary committees before they become a permanent part of the curriculum. At that point, all costs related to the new courses are sustained by SST's operational funds as part of its regular budget. Initial costs are only associated with testing the intervention. Possible funding sources for developing a minigrant program include internal funds typically associated with the provost or president's offices, or via external funds (private and public). As an institution we continue to seek external funding opportunities, but many individual faculty 
members have been able to develop their own external funding proposals based on the initial results of their redesigned courses.

While our model appears to be ambitious, we believe that it has the potential to be replicable, scalable, and attainable at different types of institutions. Results of our studies have been presented at various national conferences, as noted, and they have generated much interest. Many institutions have requested information on our model, and a few have started similar pilot projects. Our project is one of several projects that are part of the University System of Georgia Board of Regents (USG-BOR) STEM Initiative. The overall STEM initiative is aimed at promoting such projects throughout the state of Georgia by developing a Georgia STEM Network, and GGC has pledged to be a key player in this network.

Faculty members are continually encouraged to develop new ideas for research and creative activities. We are fortunate to have many young, highly motivated faculty members with fresh ideas who are inspired by positive opportunities to improve the undergraduate STEM experience. We are also fortunate to have administrators who value innovative use of educational technology, active-learning environments, and assessment-based courses. SST has been very selective in hiring faculty and administrators who are a good fit with its culture (focused on student engagement, active learning, innovative/course-embedded research experiences). We are beginning to see more collaborations between SST and other schools at GGC as faculty work to develop interdisciplinary courses.

\section{Addressing the Elephant in the Room}

Our model is addressing the elephant in the room. Our motivation to develop such a model arose partly out of necessity but also from a confluence of factors: our institutional mission, diverse student population, rapid institutional growth, and a desire to provide research opportunities to as many students as possible - as early as possible-in the undergraduate experience. We attract a highly diverse population of students, including many from groups traditionally underrepresented in STEM education. About 33 percent of GGC students are African American, 17 percent are Hispanic, 10 percent are Asian, 0.2 percent are American Indian, and 35 percent are white. First-generation students make up 50 percent of our student population, and 56 percent of the student population are females. Many of our students require financial aid (approximately 65 percent receive Pell grants), and many work a significant number of hours. Further, in just nine years, the college has grown from 118 students to 11,500 students, and enrollment is projected to reach 13,000 within the next year. Classroom space and research facilities are very limited. Given our mission and student population, it was obvious that "doing what most other institutions do" was not likely to succeed.

Students still must grapple with the uncertainty and anxiety of the research process, but they are rewarded by developing confidence as they acquire knowledge, skills, and abilities while developing STEM competencies over several successive semesters of course-based research experiences. We continue to collect and analyze assessment data and to track STEM retention, progression, and graduation rates. We plan to use this evidence to drive continuous improvement and reform. Laursen (2015) notes the challenges of assessing undergraduate research and the need for an integrated assessment approach. We hope our work will add to the body of assessment data regarding the efficacy of large-scale implementation of course-embedded research experiences using our model's four-year approach. $\mathrm{O}$

\section{Acknowledgment}

This work was supported by funds provided by the University System of Georgia Board of Regents STEM Initiative. The authors would like to thank Patrick Smallwood for his help with data analysis.

\section{References}

American Association for the Advancement of Science. 2011. Vision and Change in Undergraduate Biology Education: A Call to Action. Washington, DC. "American Chemical Society Guidelines." American Chemical Society, accessed April 8, 2016. http://www.acs.org/content/acs/en/education/policies.html.

Awong-Taylor, Judy, Clay Runck, Tirza Leader, Allison D'Costa, and Thomas Mundie. 2015. "Promoting Cultural Change: Using Mini-Grants to Incentivize Faculty to Reform Undergraduate STEM Education." American Association of Colleges and Universities (AACU) Conference on Crossing Boundaries: Transforming Stem Education. Seattle, Washington.

Bangera, Gita, and Sara E. Brownell. 2014. "Course-Based Undergraduate Research Experiences Can Make Scientific Research More Inclusive." Cell Biology Education 13(4): 602-606. doi: 10.1187/cbe.14-06-0099.

Boindala, Priya, Natasha Brewley, and Jennifer Sinclair. 2015. "Ideation to Execution: Flipping an Undergraduate Pre-Calculus Course to Create Significant Learning Experiences." In Implementation and Critical Assessment of the Flipped Classroom, edited by Abigail G. Scheg, 24-40. Hershey, PA: IGI Global.

Caudill, Lester, April Hill, Kathy Hoke, and Ovidiu Lipan. 2010. "Impact of Interdisciplinary Undergraduate Research in Mathematics and Biology on the Development of a New Course Integrating Five STEM Disciplines." CBELife Sciences Education 9(3): 212-216. doi: 10.1187-cbe.10-03-0020.

Craney, Chris, Tara McKay, April Mazzeo, Janet Morris, Cheryl Prigodich, and Robert de Groot. 2011. "Cross-Discipline Perceptions of the Undergraduate Research Experience." The Journal of Higher Education 82(1): 92-113. doi: 10 1353/jhe.2011.0000.

Goldey, Ellen, Clarence Abercrombie, Tracie Ivy, Dave Kusher, John Moeller, Doug Rayner, Charles Smith, and Natalie Spivey. 2012. "Biological Inquiry: A New Course and Assessment Plan in Response to the Call to Transform 
Undergraduate Biology." CBE-Life Sciences Education 11(4): 353-363. doi: 10.1187/cbe.11-02-0017.

Heinz, Adrian, and Allison D'Costa. 2015. "Web-animations: An Interdisciplinary Approach for Biology and Information Technology Students." IEEE Integrated STEM Education Conference. Princeton, NJ doi: 10.1109/isecon.2015.7119941.

Henry, Ronald J. 2010. "An Assessment of STEM Faculty Involvement in Reform of Introductory College Courses." Journal of College Science Teaching 39(6): 74-81.

Jones, Melanie T., Amy E. L. Barlow, and Merna Villarejo. 2010. “The Importance of Undergraduate Research for Minority Persistence and Achievement in Biology." Journal of Higher Education 81(1): 82-115. doi: 10.1353/jhe.0.0082.

Laursen, Sandra. 2015. "Assessing Undergraduate Research in the Sciences: the Next Generation." Council on Undergraduate Research Quarterly 35(3): 9-14.

Laursen, Sandra, Anne-Barrie Hunter, Elanie Seymour, Heather Thiry, and Ginger Melton. 2010. Undergraduate Research in the Sciences: Engaging Students in Real Science. San Francisco, CA: Jossey-Bass.

Leader, Tirz, Clay Runck, Greta Giles, Thomas Mundie, David Pursell, Allison D'Costa, and Judy Awong-Taylor. 2014. "Monitoring Undergraduate Research Outcomes: Designing Effective Assessments." Council on Undergraduate Research (CUR) Conference on Creating the Citizens of Tomorrow: Undergraduate Research for All. Washington, DC.

Linn, Marcia, Erin Palmer, Anne Baranger, Elizabeth Gerard, and Elisa Stone. 2015. "Undergraduate Research Experiences: Impacts and Opportunities." Science 347(6222): 627-633. doi: 10.1126/science.1261757.

Lopatto, David. 2004. "Survey of Undergraduate Research Experiences: First Findings." Cell Biology Education 3(4): 270-277. doi: 10.1187/cbe.04-07-0045.

Lopatto, David. 2007. "Undergraduate Research Experiences Support Science Career Decisions and Active Learning." CBE-Life Sciences Education 6(4): 297-306. doi: 10.1187/cbe.07-06-0039.

Lopatto, David. 2009. Science in Solution: The Impact of Undergraduate Research on Student Learning. Tucson, AZ: Research Corporation for Science Advancement.

Meso, Peter, Yan Zong Ding, and Shuting Xu. 2013. "Applying Protection Motivation Theory to Information Security Training for College Students." Journal of Information Privacy and Security 9(1): 47-67. doi: 10.1080/15536548 .2013 .10845672 .

National Research Council. 2003. Improving Undergraduate Instruction in Science, Technology, Engineering, and Mathematics: Report of A Workshop. Washington, DC: The National Academies Press.

Pacifici, Lara, and Norman Thomson. 2011. "What Do They Expect? A Comparison of Student Expectations and Outcomes of Undergraduate Research Experiences." Journal of College Science Teaching 41(1): 54-60.

Runck, Clay, David Pursell, Allison D'Costa, Greta Giles, Judy AwongTaylor, Thomas Mundie, and Tirza Leader. 2014. "A Course-embedded Model for Integrating Undergraduate Research Experiences Throughout the 4-yr Curriculum." Council on Undergraduate Research (CUR) Conference on Creating the Citizens of Tomorrow: Undergraduate Research for All. Washington, DC.

Russell, Susan. 2005. Evaluation of NSF Support for Undergraduate Research Opportunities, Survey of STEM Graduates. Menlo Park, CA: SRI International.

Russell, James, Allison D'Costa, Clay Runck, David Barnes, Alessandra Barrera, Jennifer Hurst-Kennedy, Elizabeth Sudduth, Erin Quinlan, and Mark Schlueter. 2015. "Bridging the Undergraduate Curriculum Using an Integrated Course-Embedded Undergraduate Research Experience (ICURE)." CBE-Life Sciences Education 14(1): 1-10. doi: 10.1187/cbe.14-09-0151.

Schmitz, Heather, and Karen Havholm. 2015. "Undergraduate Research and Alumni: Perspectives on Learning Gains and Post-graduation Benefits." Council on Undergraduate Research Quarterly 35(3): 15-22.

Shaffer, Christopher, Consuelo Alvarez, April Bednarski, et al. 2014. “A Course-Based Research Experience: How Benefits Change with Increased Investment in Instructional Time." CBE-Life Sciences Education 13(1): 111130. doi: 10.1187/cbe-13-08-0152.

Sloop, Joseph, Leonard Anagho, Patrick Coppock, Greta Giles, Sang Park, Richard Pennington, David Pursell, Gillian Rudd, and Mai Yin Tsoi. 2013. "Conformational Analysis, Modeling, Stereochemistry and Optical Activity of Cyclohexane Derivatives." Journal of Laboratory Chemical Education 1(3): 39-44.

\section{Judy Awong-Taylor}

Georgia Gwinnett College, jawongta@ggc.edu

Judy Awong-Taylor is a professor of biology at Georgia Gwinnett College (GGC) and currently co-principal investigator and project director for the University System of Georgia's (USG) STEM Initiative II grant that focuses on increasing graduation rates for STEM majors by increasing students' exposure to undergraduate research. She has been actively involved in undergraduate research, student-centered learning, and K-16 collaborative activities. Her current interests center on STEM education and, as a PULSE (Partnership for Undergraduate Life Sciences Education) Leadership Fellow, she is actively involved in efforts focused on change at the departmental and institutional levels.

Allison D'Costa is an associate professor of biology at GGC and co-principal investigator for the USG's STEM Initiative II grant. She has postdoctoral experience in genetics, neurobiology, and developmental biology, and has been actively involved in redesigning traditional labs to be inquiry-and research-based. She has been awarded internal mini-grants to develop research-based lab modules for freshman and sophomore students.

Greta Giles is an assistant professor of chemistry at the University of North Georgia with more than ten years of teaching experience in higher education. She spent three years as the coordinator of a community college math-and-science learning center, where she trained and supervised peer tutors and supplemental instruc- 
tion leaders. Giles is co-principal investigator on the USG STEM Initiative II grant and has been a co-PI on three mini-grants used to design research modules for incorporation into the curriculum.

Tirza Leader has a PhD in social psychology with more than ten years of teaching experience in higher education, including heading a faculty consultancy group at the University of Kent. During that time she designed, implemented, and analyzed various assessments for government agencies and private business. Project designs included literature reviews, assessments of employees' initiatives, and evaluation of the effectiveness of national campaigns.

David Pursell is a professor of chemistry and co-principal investigator for the USG STEM Initiative II grant. His experimental research group investigates environmental chemistry issues involving the campus ecosystem and includes both college and highschool student researchers.

Clay Runck is an assistant professor of biology and a co-principal investigator for the USG's STEM Initiative II grant. He has been actively involved in undergraduate field-ecology research, student-centered learning, and is co-instructor for a STEM service-learning internship in which junior and senior STEM majors teach a semester-long, inquiry-based enrichment program designed to implement fifth grade science curriculum standards

Thomas Mundie is the founding dean of the GGC School of Science and Technology and a professor of biology. He is currently the principal investigator for the USG STEM Initiative II grant. With more than 30 years of higher education experience, he is involved in research on undergraduate success in STEM majors, particularly for students from underserved populations.

\section{doi: $10.18833 /$ curq/37/1/4}

